Open Access

\title{
Enhanced chemokine-receptor expression, function, and signaling in healthy African American and scleroderma-patient monocytes are regulated by caveolin-1
}

Rebecca Lee ${ }^{1}$, Charles Reese ${ }^{1}$, Beth Perry ${ }^{1}$, Jonathan Heywood ${ }^{1}$, Michael Bonner ${ }^{1}$, Marina Zemskova ${ }^{1}$, Richard M. Silver ${ }^{1}$, Stanley Hoffman ${ }^{1,2}$ and Elena Tourkina ${ }^{1,2^{*}}$

\begin{abstract}
Background: A major health disparity suffered by African Americans (AA) is a predisposition toward fibrotic diseases of the skin, lung, and other organs. We previously showed that healthy AA and scleroderma (systemic sclerosis (SSC)) patient monocytes share biochemical and functional differences from control Caucasian (C) monocytes that may predispose AA to SSc. The central difference is a decrease in caveolin-1. Low caveolin-1 levels promote monocyte migration, their differentiation into fibrocytes, and fibrocyte recruitment into fibrotic tissues. Here we have greatly expanded our studies on the mechanism of action in fibrosis of caveolin-1 in AA and SSc monocytes.

Results: Expression of chemokine receptors (CCR1, CCR2, CCR3) is enhanced in healthy AA monocytes compared to healthy $\mathrm{C}$ monocytes and further increased in SSC monocytes. A parallel increase in function occurs assessed by migration toward chemokines MCP-1 and MCP-3. Chemokine-receptor expression and function are inhibited by the caveolin-1 scaffolding domain peptide (CSD) via its action as a surrogate for caveolin-1. Cells bearing chemokine receptors accumulate to high levels in fibrotic lung and skin tissue from SSC patients and from mice treated with bleomycin. This accumulation is almost completely blocked in mice treated with CSD. In signaling studies, Src activation is enhanced in AA monocytes compared to C monocytes and further increased in SSC monocytes. Lyn is also highly activated in SSc monocytes. Src and Lyn activation are inhibited by CSD. Src and Lyn's roles in monocyte migration were demonstrated using specific inhibitors.

Conclusions: To the best of our knowledge, this is the first report that the expression and function of CCR1, CCR2, and CCR3 are upregulated in monocytes from healthy AA and from SSC patients via molecular mechanisms involving caveolin-1, SrC/Lyn, and MEK/ERK. The results suggest that the migration/recruitment of monocytes and fibrocytes into fibrotic tissues, mediated at least in part by CCR1, CCR2, and CCR3, plays a major role in the progression of lung and skin fibrosis and in the predisposition of AA to fibrotic diseases. Our findings further suggest that chemokine receptors and signaling molecules, particularly caveolin-1, that control their expression/function are promising targets for treating fibrotic diseases.
\end{abstract}

\footnotetext{
* Correspondence: tourkine@musc.edu

${ }^{1}$ Division of Rheumatology and Immunology, Department of Medicine,

Medical University of South Carolina, 96 Jonathan Lucas Street Suite 816, MSC 637, Charleston, SC 29425, USA

2Department of Regenerative Medicine and Cell Biology, Medical University of South Carolina, 96 Jonathan Lucas Street Suite 816, Charleston, SC 29425 USA
} 


\section{Background}

A major health disparity affecting African Americans (AA) is a predisposition toward fibrotic diseases of the skin, lung, and other organs. AA scleroderma (systemic sclerosis, SSc) patients have a younger age of disease onset, higher probability of the more severe diffuse cutaneous form of the disease, and higher mortality. AA SSc patients are significantly more likely than Caucasian $(C)$ SSc patients to exhibit impaired lung function [1-8]. While there has been a considerable focus on AA SSc patients, there have been few studies on underlying differences between healthy AA and $\mathrm{C}$ that might explain the predisposition of AA to SSc and interstitial lung disease (ILD). In one study, levels of the profibrotic cytokine transforming growth factor $\beta$ (TGF $\beta$ ) were twice as high in serum from healthy AA compared to healthy $C$ [9].

We recently identified several parameters in which healthy AA are similar to SSc patients that may predispose AA to fibrosing diseases, e.g., SSc [10]. The central observation was a diminution in the master regulatory protein caveolin-1 in monocytes from healthy AA compared to healthy C. A greater loss of monocyte caveolin1 is linked to lung and skin fibrosis in bleomycin-treated mice and in SSc-ILD and IPF patients [11-14]. The low level of caveolin-1 in AA and SSc monocytes strongly promotes their migration toward several chemokines and their differentiation into $\alpha$-smooth muscle actin (ASMA)positive fibrocytes. Both of these functions are blocked by the caveolin-1 scaffolding domain peptide (CSD), which enters cells and compensates for the lack of caveolin-1.

Monocyte migration in vitro models their recruitment in vivo into tissues undergoing inflammation and fibrosis. In both cases, chemokines provide a chemotactic signal to cells by binding to their specific cell-surface receptors. The molecular mechanism through which low caveolin-1 enhances monocyte migration involves the accumulation of chemokine receptors such as CXCR4 and CCR5 [12, 15]. This accumulation may result from either enhanced expression or decreased turnover. Signaling downstream from the chemokine receptor-ligand interaction is mediated by several pathways including $G$ protein-coupled receptor signaling, Src-family signaling, and MAPK family signaling $[16,17]$. Src-family kinases are also important in fibrosis due to their ability to regulate ECM protein expression by dermal fibroblasts.

Here we expand our study of the regulation of AA and SSc monocyte migration to additional chemokines, chemokine receptors, and signaling pathways. In particular, we have studied chemokine receptors CCR1, CCR2, and CCR3 and the chemokines MCP-1 (also known as CCL2, binds to CCR2) and MCP-3 (also known as CCL7; binds to CCR1, CCR2, and CCR3). Both MCP-1 and MCP-3 are upregulated in SSc [18]. To the best of our knowledge, this is the first report that the expression and function of
CCR1, CCR2, and CCR3 are upregulated in monocytes from healthy AA and from SSc patients via molecular mechanisms involving caveolin-1, Src/Lyn, and MEK/ERK signaling.

\section{Results}

CCR1, CCR2, and CCR3 expression and function are enhanced in monocytes from healthy AA and SSC patients We reported that expression of the chemokine receptor CXCR4 is enhanced in healthy AA monocytes compared to healthy $\mathrm{C}$ monocytes and that it is present at a still higher level in SSc patient monocytes [10]. Similarly, we showed enhanced CXCR4 function in that we observed enhanced migration of healthy AA and SSc patient monocytes toward the CXCR4 ligand SDF-1. To expand on these studies, here we examine additional chemokine receptors: CCR1, CCR2, and CCR3. Western blot analyses reveal increases in the expression of all three receptors in AA and SSc monocytes (Fig. 1). As with CXCR4, treatment of AA and SSc monocytes with CSD decreases the expression of these chemokine receptors down to the level observed in $\mathrm{C}$ monocytes (Fig. 1c, d). The results of these Western blot experiments were validated in IHC experiments that demonstrated decreased levels of caveolin-1 and increased levels of CCR1, CCR2, and CCR3 in AA and SSc monocytes compared to $\mathrm{C}$ monocytes (Fig. 2).

To determine whether chemokine receptor function is also enhanced in healthy AA and SSc patient monocytes, we evaluated monocyte migration toward chemokines MCP-1, MCP-3, and SDF-1. Almost no migration occurred in the absence of chemokines (Fig. 3, "Medium"). For each chemokine, the basal rate of migration was higher for healthy AA monocytes (Fig. 3b) than for healthy $\mathrm{C}$ monocytes (Fig. 3a) and higher still for SSc monocytes (Fig. 3c), especially for SDF-1 and MCP-1. When migration was examined in cells activated with TGF $\beta$, again migration toward each chemokine was higher for healthy AA monocytes than for healthy $\mathrm{C}$ monocytes. In all cases, migration was strongly inhibited when cells were treated with CSD.

\section{CCR1, CCR2, and CCR3 are upregulated in SSc patient lung and skin tissue}

Given that CCR1, CCR2, and CCR3 are upregulated on SSc monocytes, we also compared their expression in SSc and control lung and skin tissue. To begin to determine which cell types express these chemokine receptors in SSc, these studies were performed as double-label experiments with the monocyte/macrophage marker CD68 or with the collagen chaperone HSP47 (which serves as a marker for fibrocytes and fibroblasts). Little staining was observed in control tissue, except occasionally in alveolar macrophages; however, prevalent double staining 


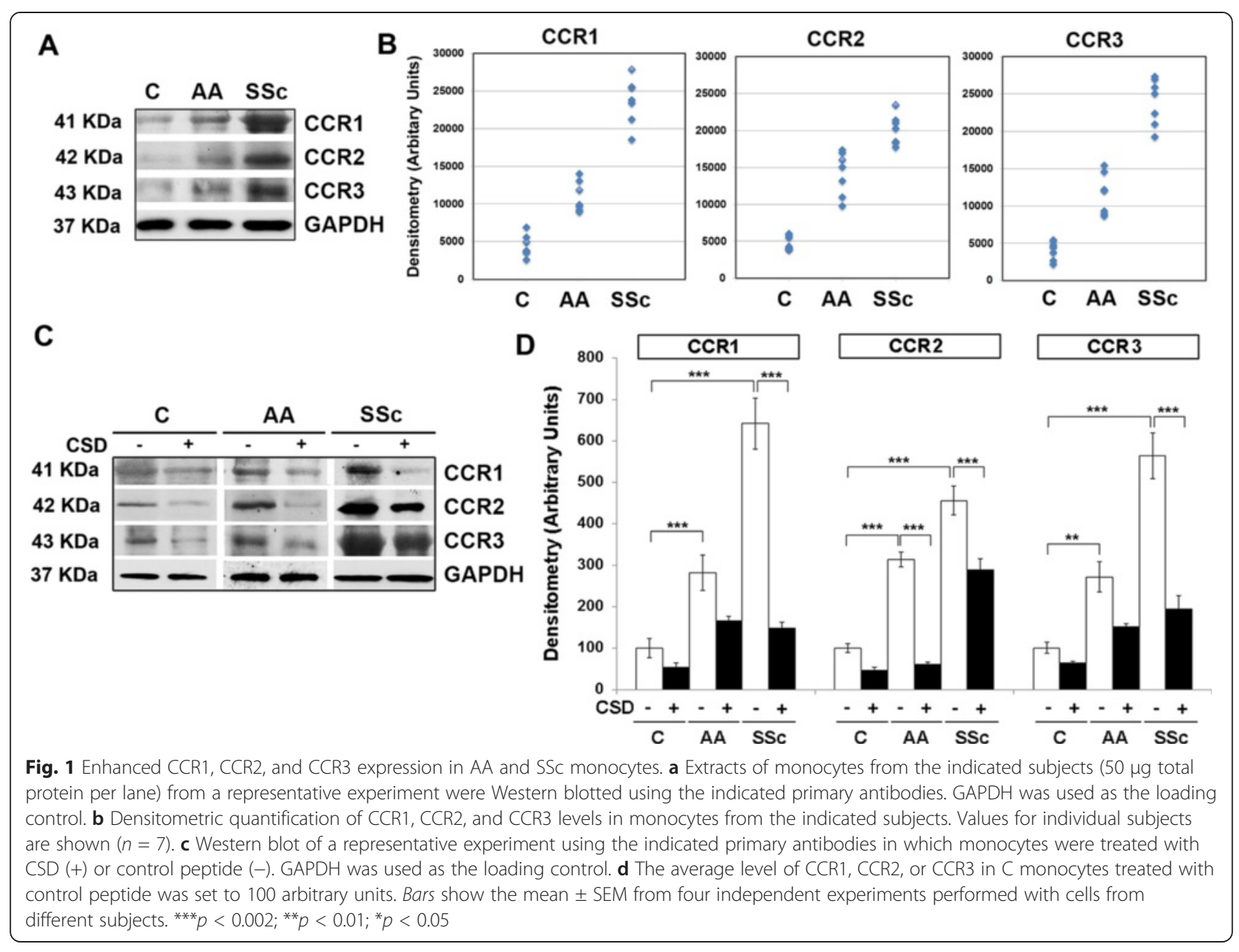

was observed in SSc skin (Fig. 4, CD68 and chemokine receptors; Fig. 5, HSP47 and chemokine receptors) and lung tissue (Fig. 6, HSP47 and chemokine receptors). It may be noteworthy that among CCR1, CCR2, and CCR3/HSP47 double staining, CCR2 double staining was the most prominent in SSc skin (Fig. 5d) and the least prominent in SSc lung (Fig. 6d). In contrast, CCR2/ CD68 double staining was the least prominent in SSc (Fig. 4d).

\section{Upregulation of CCR1, CCR2, and CCR3 in fibrotic mouse tissues is reversed by CSD}

We recently used a mouse model system in which bleomycin is delivered systemically by subcutaneously implanted osmotic minipumps (Pump Model) to induce fibrosis in multiple organs including lungs and skin [19], and to demonstrate that the development of fibrosis in both lungs and skin is blocked by treatment with CSD $[15,20]$. Here we examine the expression of CCR1, CCR2, and CCR3 in this murine bleomycin pump model. As in SSc patients, double staining for these molecules and HSP47 in fibrotic skin (Fig. 7) and lung
(Fig. 8) tissue was greatly enhanced compared to control tissue. Treatment with CSD brought the level of expression of CCR1, CCR2, and CCR3 down essentially to the level observed in control (saline-treated) animals (Figs. 7 and 8). These observations support the idea that CSD blocks the progression of fibrosis by inhibiting the recruitment/accumulation in target tissues of cells expressing CCR1, CCR2, and/or CCR3.

\section{Enhanced Src and Lyn activation in AA and SSC monocytes}

To identify signaling mechanisms responsible for the hypermigration of SSc and AA monocytes, we studied kinases activated by chemokine-receptor interactions. We demonstrated that ERK is activated in AA and SSc monocytes $[10,12]$. Here we show that both Src and Lyn are highly activated in SSc monocytes, and that Src, but not Lyn, is also activated in AA monocytes (Fig. 9a, b). CSD treatment of monocytes inhibited Src and Lyn activation in SSc monocytes and Src activation in AA monocytes (Fig. 9c-e). Thus, Src and Lyn may be critical players in the altered behavior of SSc and AA monocytes. 


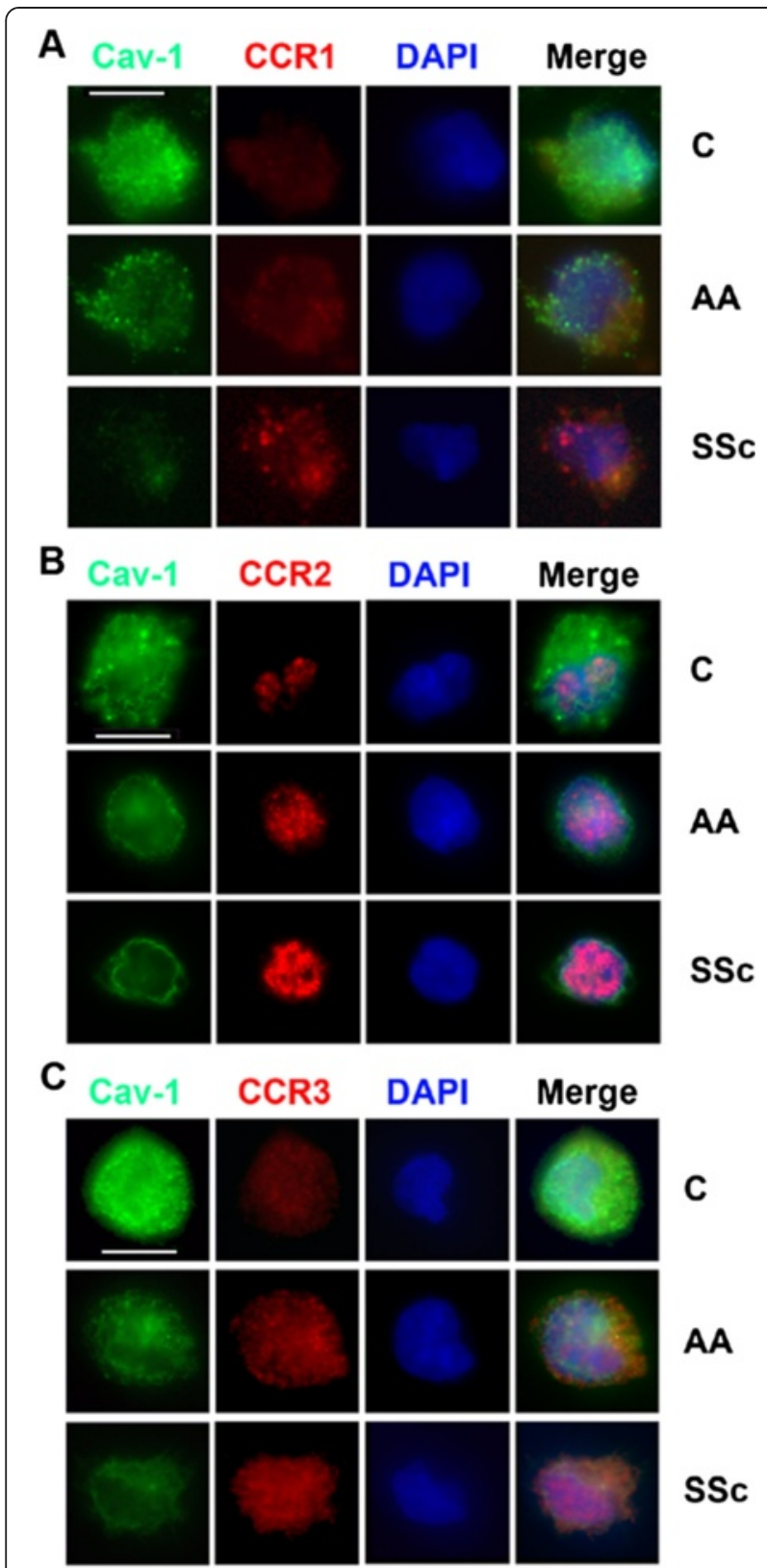

Fig. 2 Demonstration by immunocytochemistry of increased expression of CCR1, CCR2, and CCR3 and decreased expression of caveolin-1 by AA and SSC monocytes. C, AA, and SSC monocytes were stained green for caveolin-1 (Cav-1) and red for CCR1 (a), CCR2 (b), or CCR3 (c) as described in the "Methods" section. Nuclei were counterstained using DAPI (blue). Representative images are shown typical of the results obtained in four independent experiments in each category. Bars $=5 \mu \mathrm{m}$

MEK/ERK and Src-family inhibitors inhibit monocyte migration

To validate the functional importance of MEK/ERK and Src/Lyn in monocyte migration, we used the MEK/ERK inhibitor U0126 and Src/Lyn inhibitors PP2 and SU6656. All these reagents significantly inhibited SSc monocyte

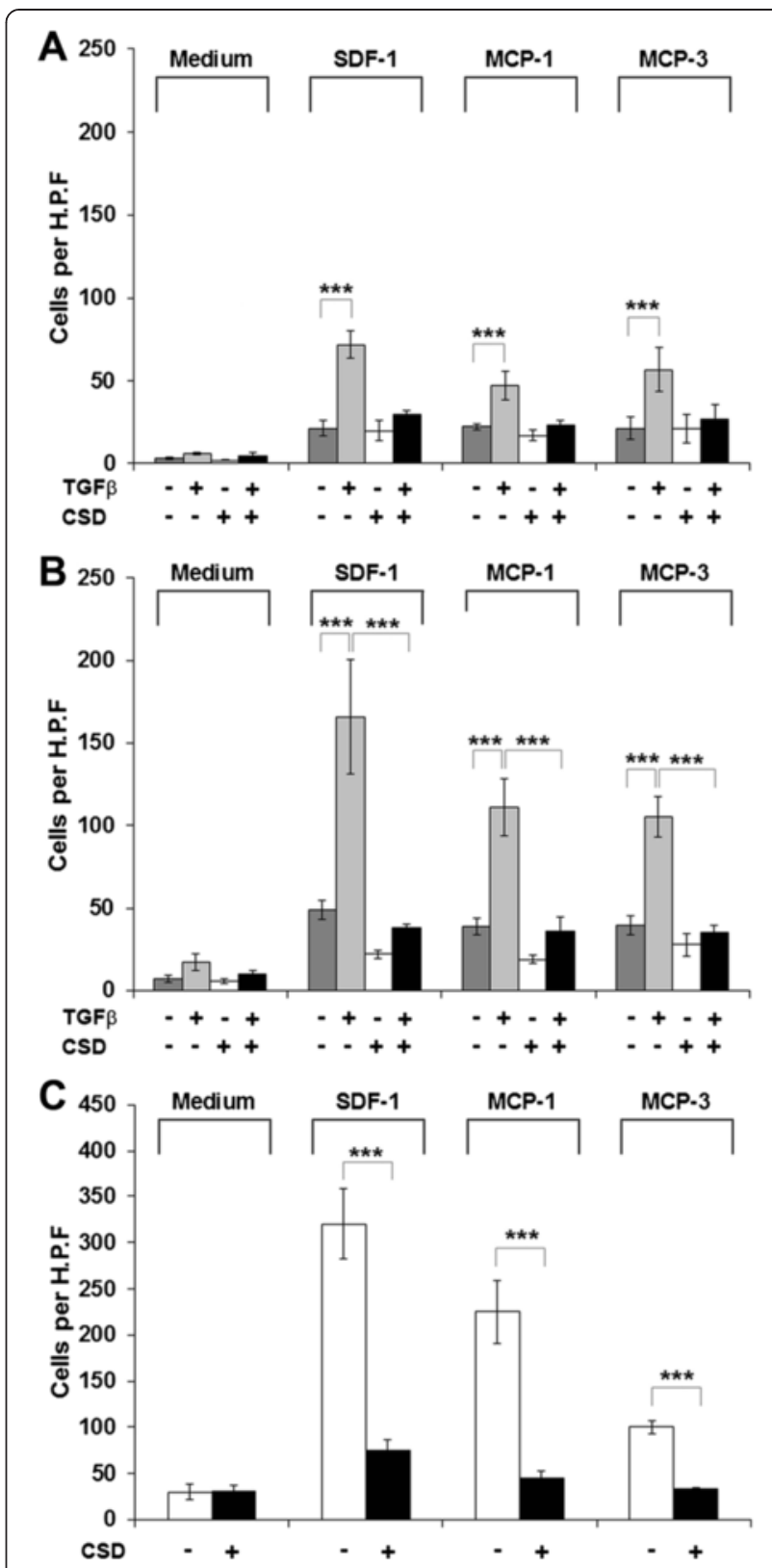

Fig. 3 Migration toward various chemokines. Migration experiments were performed as described in the "Methods" section using C (a), AA (b), or SSc (c) monocytes. Cells were treated with TGF $\beta$ and CSD as indicated. Chemokines used as chemoattractants (and medium only control) are indicated. Data are expressed in terms of number of migrating cells counted per high power field. Bars show the mean level of migration \pm SEM from four different subjects in each category determined in independent experiments. ${ }^{* *} p<0.002$; ${ }^{* *} p<0.01 ;{ }^{*} p<0.05$

migration toward SDF-1, MCP-1 and MCP-3, although not as effectively as CSD (Fig. 10a). Similarly, all these reagents significantly inhibited the migration of TGF $\beta$ activated $\mathrm{C}$ monocytes, although again, not as effectively as CSD (Fig. 10b-d). Neither CSD nor these reagents significantly inhibited the low level of basal migration 


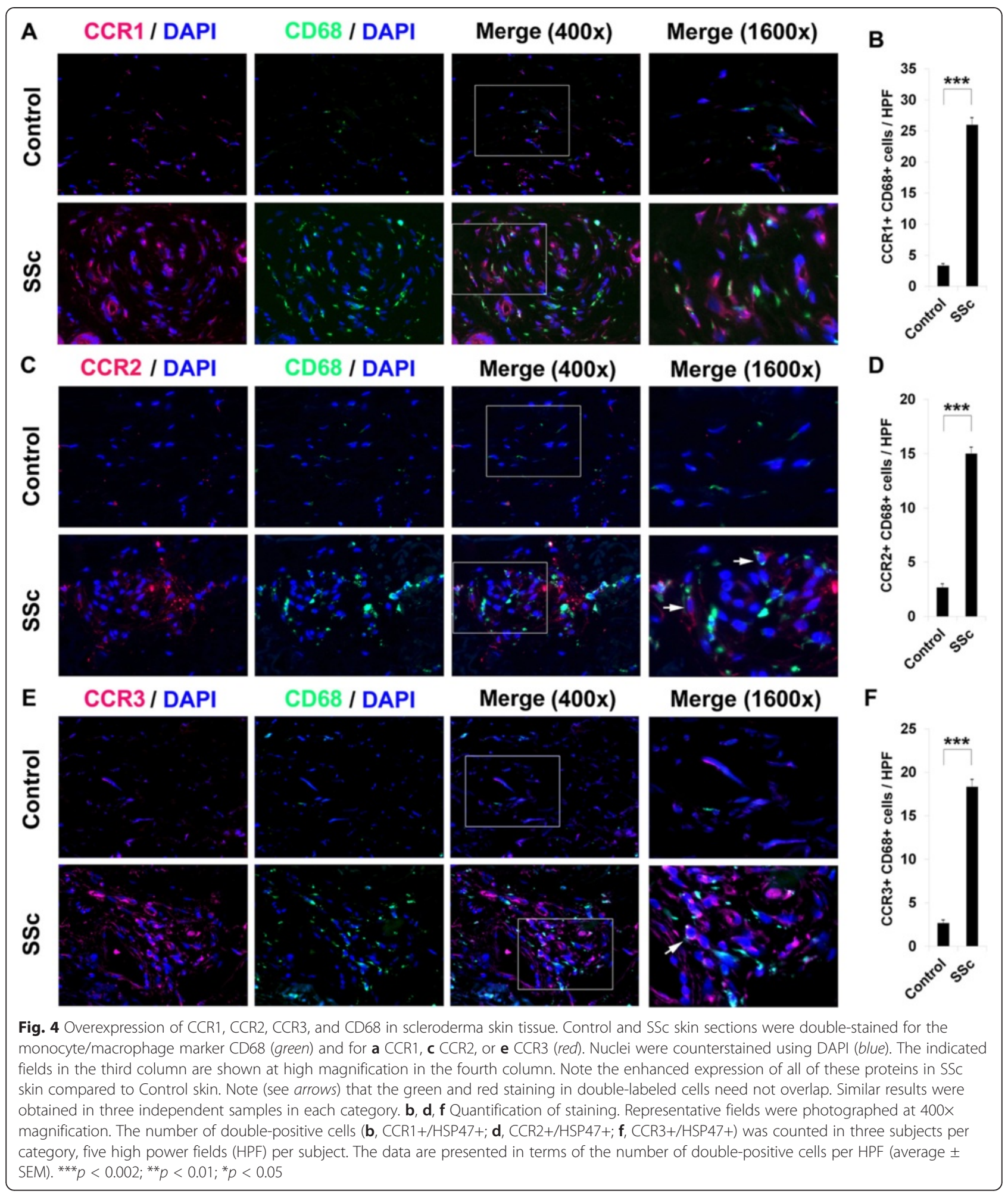

observed in control $\mathrm{C}$ monocytes not activated with TGF $\beta$. While CSD did significantly inhibit the migration of control AA monocytes (not treated with TGF $\beta$ ) [10], U0126, PP2, and SU6656 did not significantly inhibit their migration (data not shown). It is likely that CSD is more effective than U0126, PP2, or SU6656 in inhibiting migration because CSD inhibits multiple signaling cascades while each of these reagents inhibits only a single cascade. 


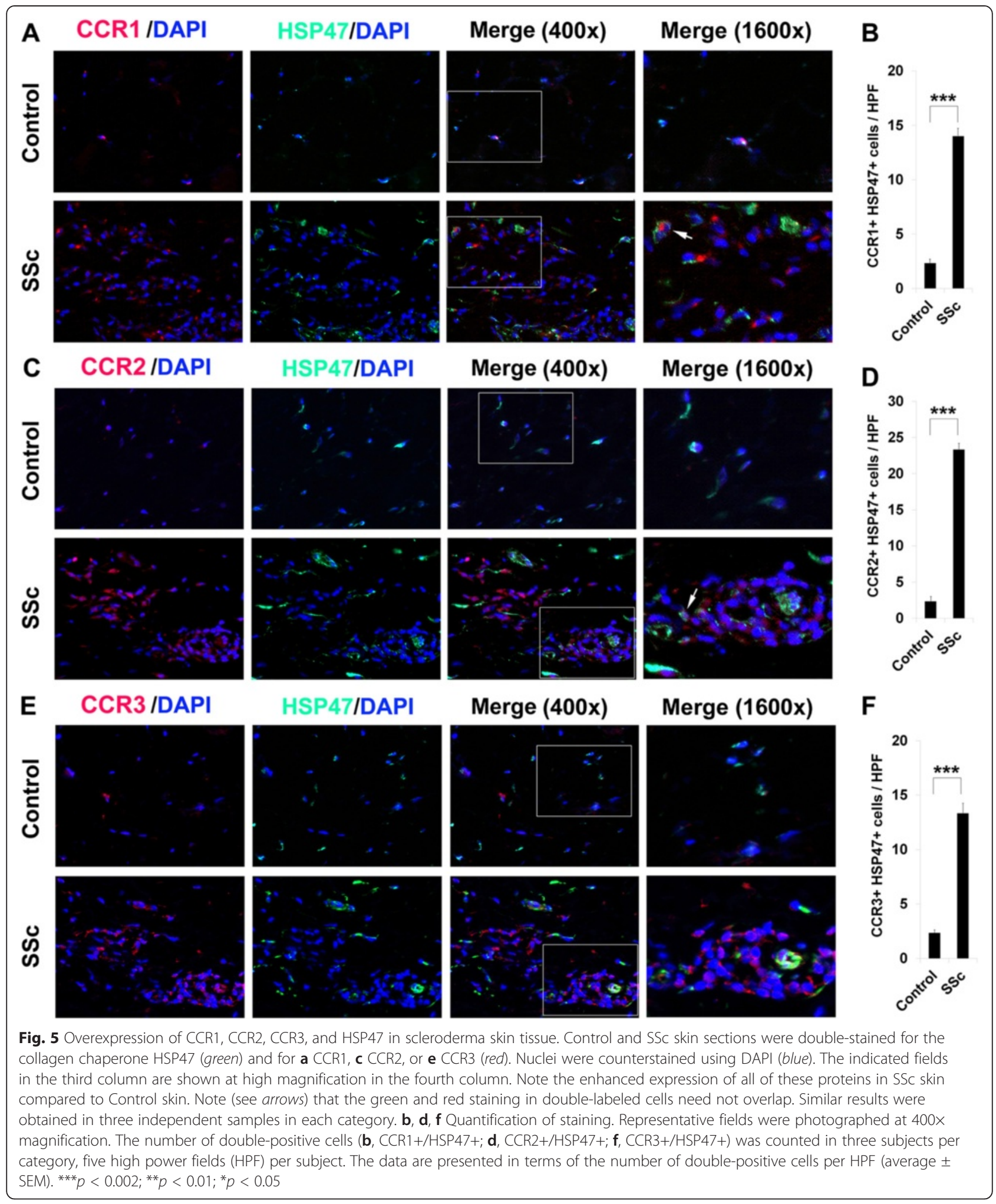

\section{Discussion}

In previous studies, we showed that caveolin-1 levels are low in monocytes from SSc patients and from healthy AA compared to healthy $C[10,12]$. Profibrotic features associated with monocytes from both SSc-ILD and healthy AA subjects include the enhanced expression of chemokine receptors CXCR4 and CCR5, enhanced migration toward their respective chemokine ligands (SDF- 


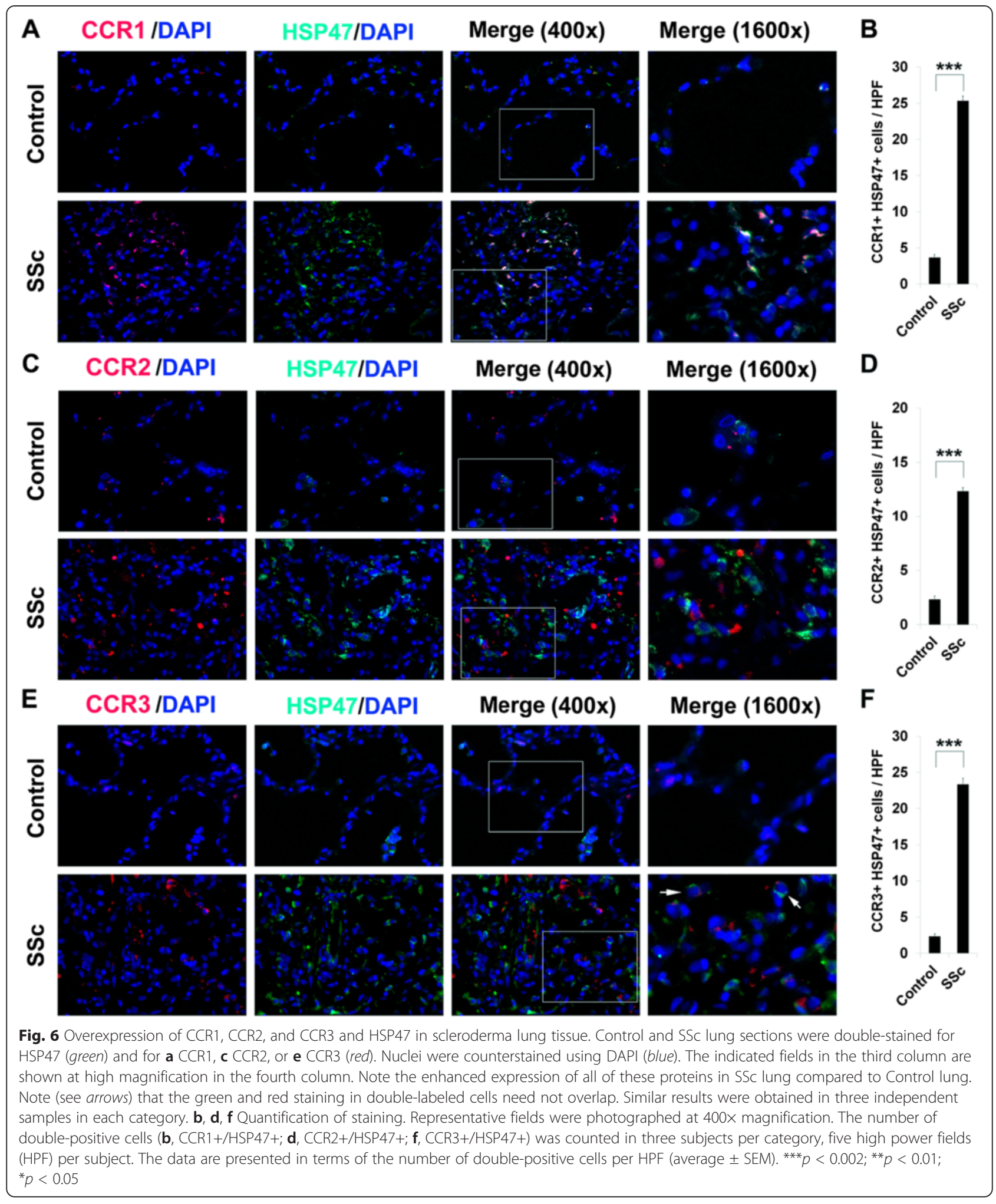

1 for CXCR4, MIP- $1 \alpha$ and MIP-1 $\beta$ for CCR5), and enhanced differentiation into fibrocytes $[10,12,19]$. All of these features were linked to low caveolin-1 expression by the fact that they were reversed by restoring caveolin-
1 function with the CSD. Here we greatly expand on these studies, demonstrating: (1) the enhanced expression of chemokine receptors CCR1, CCR2, and CCR3 by $\mathrm{AA}$ and SSc-ILD monocytes and the reversal of the 


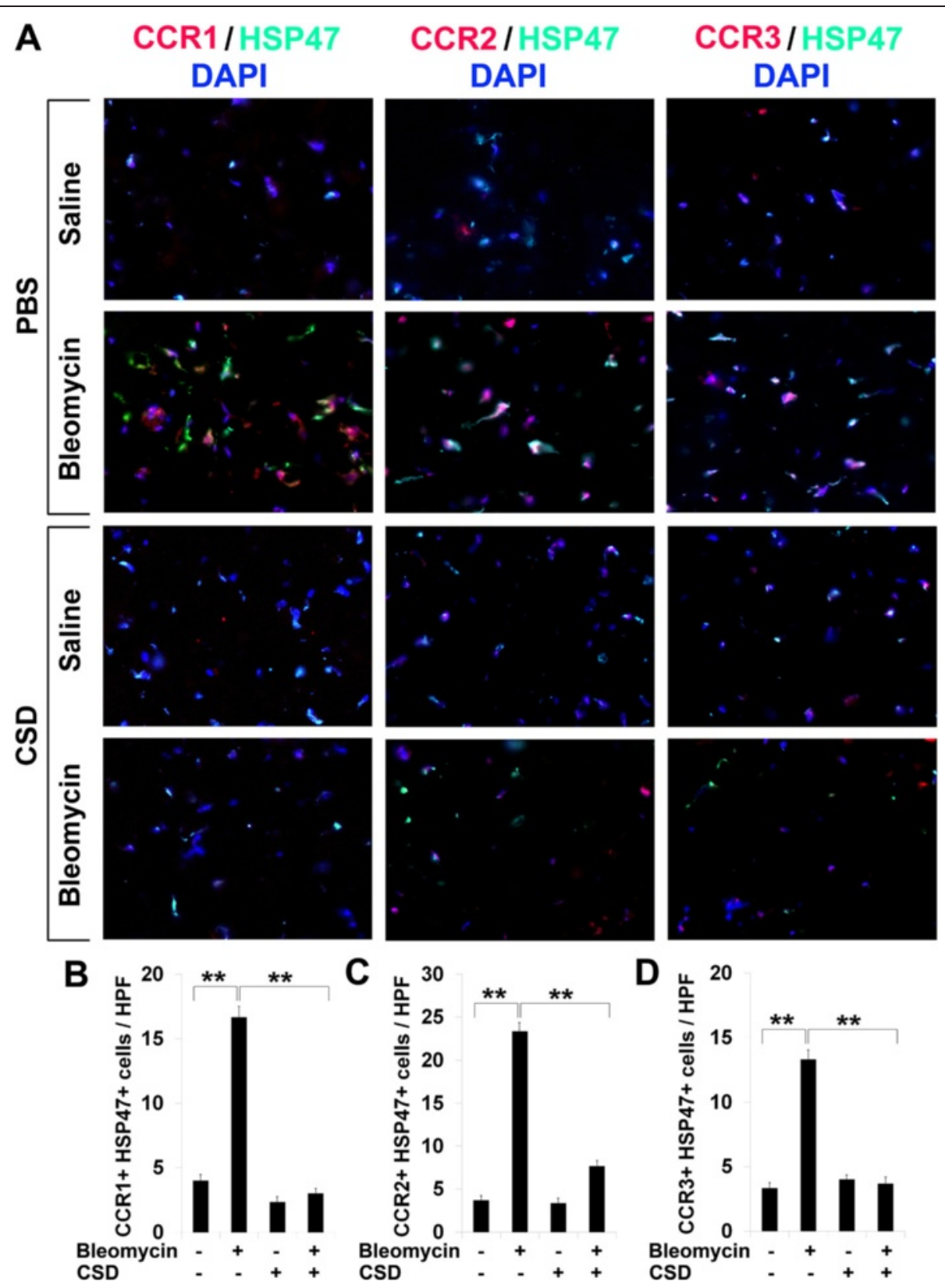

Fig. 7 Overexpression of CCR1, CCR2, and CCR3 in fibrotic mouse skin is reversed by CSD. a Skin tissue sections from mice treated systemically with bleomycin or vehicle and injected daily i.p. with CSD or vehicle were double-stained for CCR1, CCR2, or CCR3 (red) and for HSP47 (green). Nuclei were counterstained using DAPI (blue). Note the enhanced expression of all of these proteins in the skin tissue of bleomycin-treated mice and that CSD treatment almost completely blocked the accumulation of these proteins. Similar results were obtained in three independent mice in each category. b-d Quantification of staining. Representative fields were photographed at 400x magnification. The number of double-positive cells (b, CCR1+/HSP47+; $\mathbf{c}$, CCR2+/HSP47+; d, CCR3+/HSP47+) was counted in three subjects per category, five high power fields (HPF) per subject. The data are presented in terms of the number of double-positive cells per HPF (average $\pm \mathrm{SEM}$ ). ${ }^{* * *} p<0.002 ;{ }^{* *} p<0.01 ;{ }^{*} p<0.05$

enhanced expression by restoring caveolin-1 function with CSD; (2) the enhanced migration of AA and SScILD monocytes toward chemokines MCP-1 and MCP-3 and the reversal of the enhanced migration by CSD; (3) enhanced Lyn/Src signaling in AA and SSc-ILD monocytes, its reversal by CSD, and the use of specific inhibitors to demonstrate the regulation of monocyte migration by Lyn/Src and MEK/ERK; (4) the overexpression of CCR1, CCR2, and CCR3 in SSc skin and lung tissue; and (5) the overexpression of CCR1, CCR2, and CCR3 in fibrotic murine skin and lung tissue generated by systemic bleomycin delivery using implanted osmotic minipumps, and the reversal of this overexpression by treatment with CSD. 


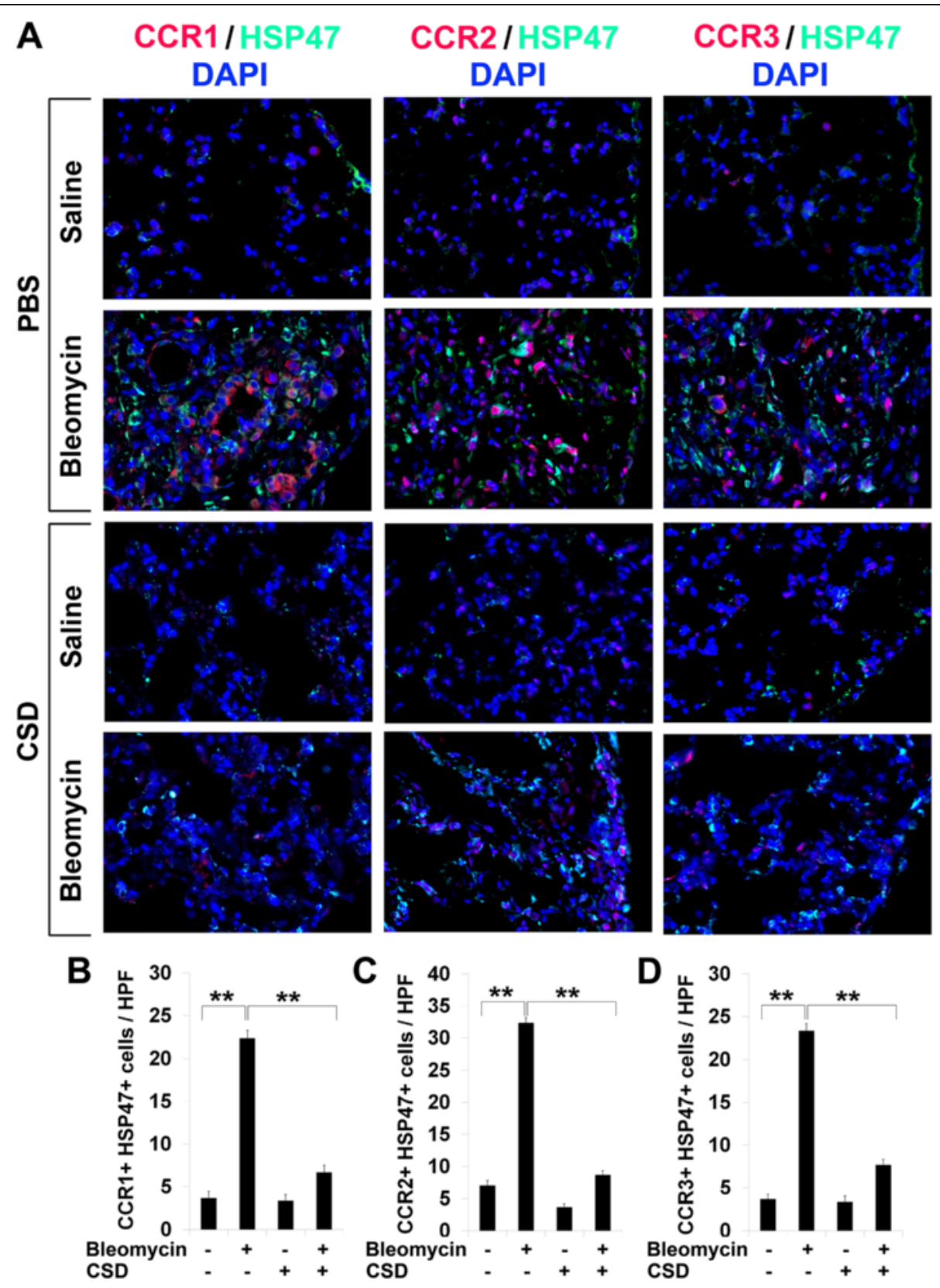

Fig. 8 Overexpression of CCR1, CCR2, and CCR3 in fibrotic mouse lung tissue is reversed by CSD. a Lung tissue sections from mice treated systemically with bleomycin or vehicle and injected daily i.p. with CSD or vehicle were stained for CCR1, CCR2, or CCR3 (red) and for HSP47 (green). Nuclei were counterstained using DAPI (b/ue). Note the enhanced expression of all of these proteins in the lung tissue of bleomycin-treated mice and that CSD treatment almost completely blocked the accumulation of these proteins. Similar results were obtained in three independent mice in each category. b-d Quantification of staining. Representative fields were photographed at 400x magnification. The number of double-positive cells (b, CCR1+/HSP47+; c, CCR2+/HSP47+; d, CCR3+/HSP47+) was counted in three subjects per category, five high power fields (HPF) per subject. The data are presented in terms of the number of double-positive cells per HPF (average \pm SEM). ${ }^{* *} p<0.002 ;{ }^{* *} p<0.01 ;{ }^{*} p<0.05$

CCR1, CCR2, and CCR3 are expressed on a variety of classes of leukocytes. Here we have focused on their expression by monocytes. To the best of our knowledge, there have been few previous reports related to their enhanced expression by monocytes from SSc patients and healthy AA subjects. At the mRNA level, CCR1 expression was enhanced in monocytes from SSc patients with PAH $[21,22]$. No data was presented at the protein level. CCR2 expression detected by immunohistochemistry was observed to be upregulated in earlystage diffuse cutaneous SSc skin by a variety of cell types including macrophages, myofibroblasts, pericytes, 


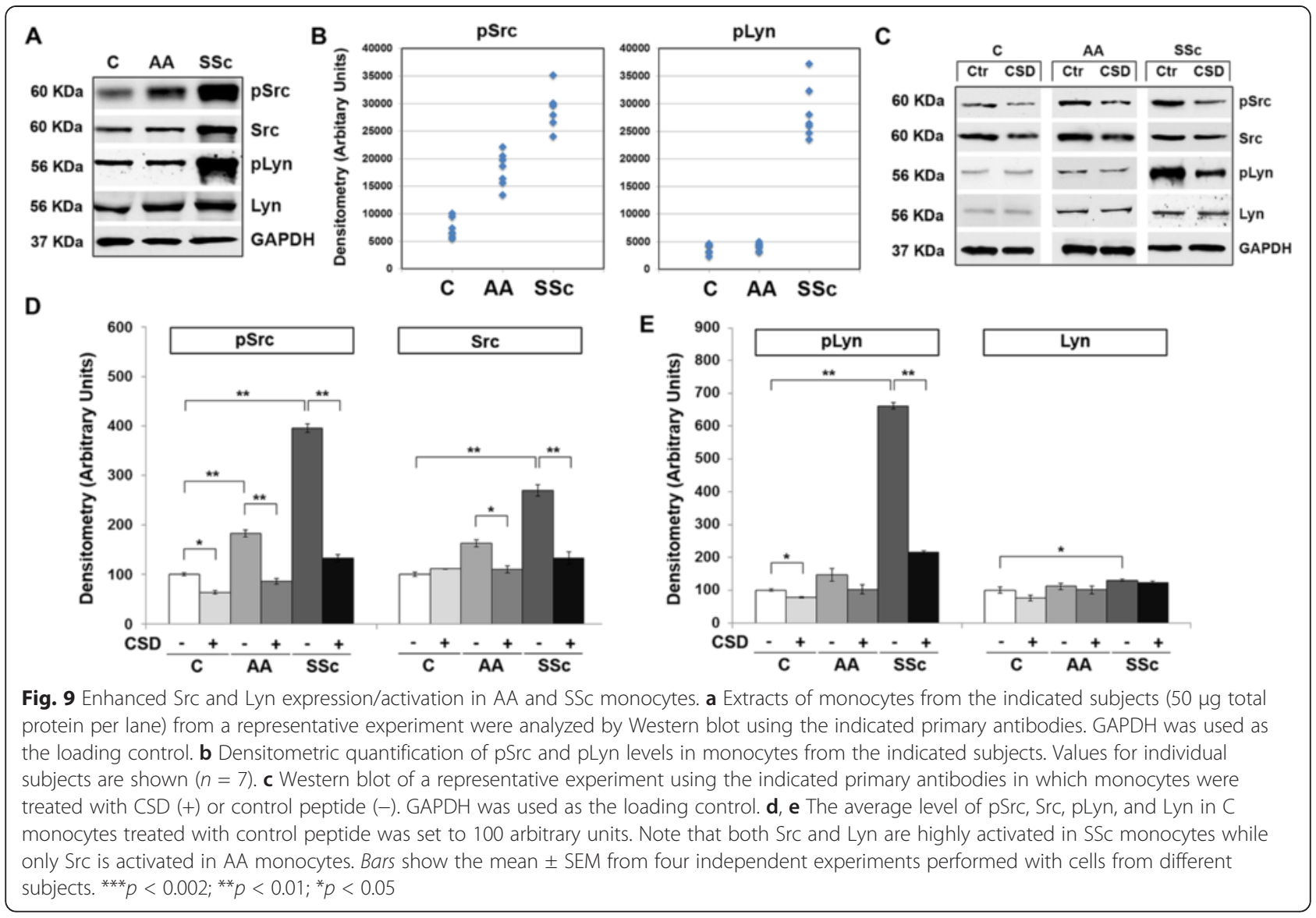

lymphocytes, and endothelial cells [23]. We also find a major upregulation of CCR2 in SSc skin in the fibrocytefibroblast lineage (HSP47+ cells). Interestingly, the number of double-positive cells in this lineage in the lungs is greater for CCR1 and CCR3 than for CCR2. Overall, comparing double staining with the monocyte/macrophage marker CD68 to double staining with HSP47 suggests that the various cell types that express chemokine receptors accumulate differentially during fibrosis.

Although key receptors can be differentially expressed on human and murine cells $[24,25]$, we find that CCR1, CCR2, and CCR3 are all expressed at high levels in both human and mouse fibrotic skin and lung tissue. Moreover, we find that the overexpression of these receptors is inhibited when mice are treated with CSD. Previous studies in mouse model systems are also consistent with the importance of these chemokine receptors in fibrosing disease. For example, antibodies against CCR1 delivered i.v. enhanced the survival of mice treated with bleomycin while inhibiting the accumulation in their lungs of collagen and inflammatory cells [26]. Experiments using CCR2 knockout mice demonstrated that CCR2 plays a major role in the recruitment of fibrocytes into the airspace of mice in which fibrosis was induced using FITC [27]. In yet another model, the overproduction of collagen induced by injection of TGF $\beta$ into the skin was significantly reduced in CCR2 knockout mice [28].

Chemokines MCP-1 and MCP-3 are present at high levels in the serum and bronchoalveolar lavage fluid of SSc patients and are expressed at high levels by SSc fibroblasts [23, 29-32]. Among SSc patients, high levels of MCP-1 and MCP-3 are associated with worse clinical outcomes. In addition to their role as chemoattractants of inflammatory cells into target tissues, MCP-1 and MCP-3 may be important in fibrosis as initiators of signaling cascades resulting in collagen overexpression $[18,30,33,34]$. While some studies show direct effects of MCP-1 and MCP-3 on collagen expression by fibroblasts $[30,34,35]$, another study proposes that MCP-1 indirectly promotes the expression of collagen by fibroblasts by activating the expression of IL- 4 by T cells [33]. In turn, this IL-4 is responsible for increasing collagen production by fibroblasts.

Relatively little is known about the signaling pathways that link relative caveolin-1 deficiency in SSc and AA monocytes to the enhanced ability of these cells to migrate toward various chemokines and to differentiate into fibrocytes. We reported the importance of MEK/ ERK signaling $[10,12]$ in these cell functions. Here we have studied the Src-family kinases Src and Lyn. We find 


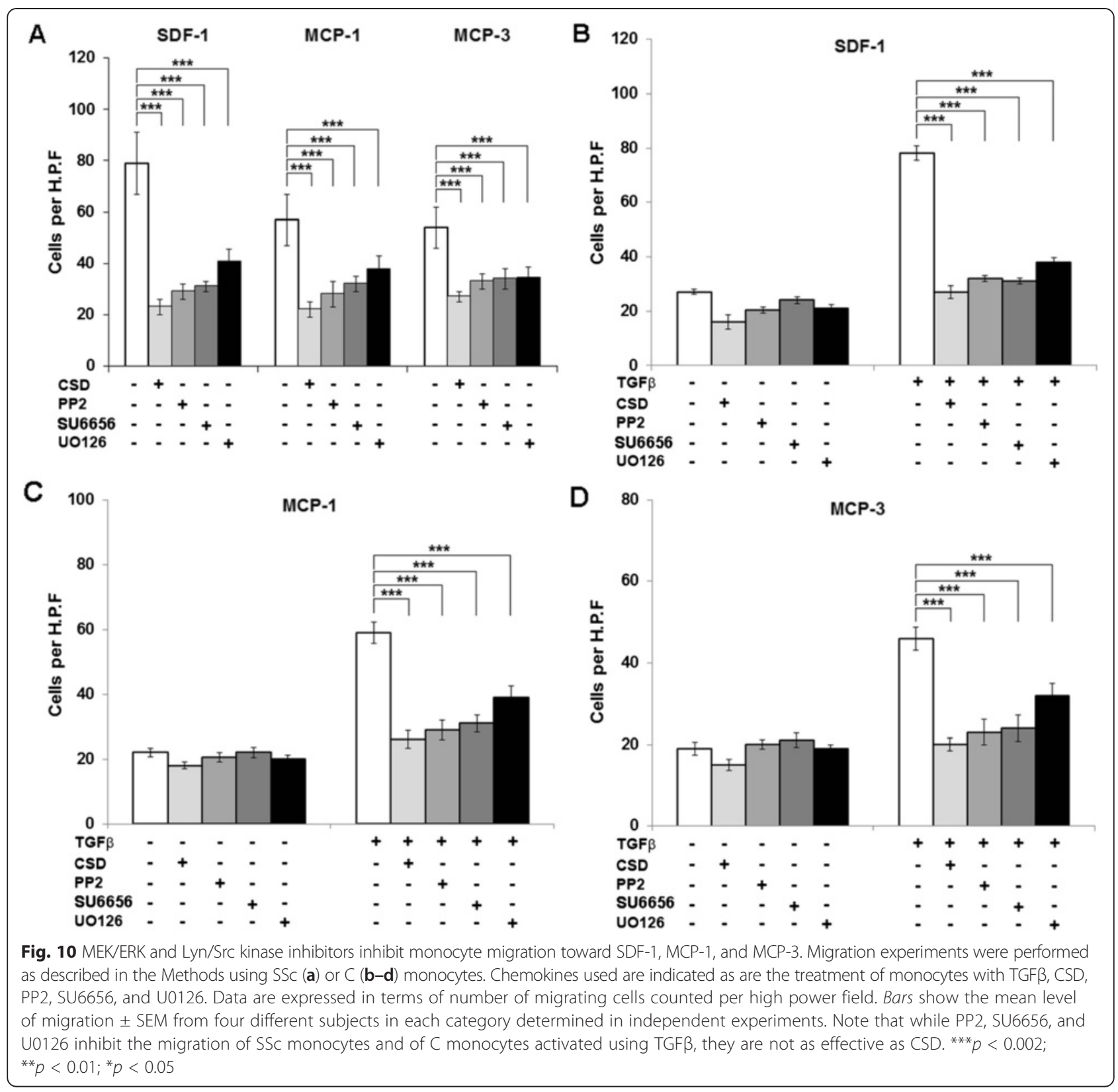

that Src and Lyn are hyperactivated in SSc monocytes and that Src is activated in AA monocytes. In both cases, Src and Lyn activation are reversed by treating cells with CSD. In addition, we find that the Src/Lyn inhibitors PP2 and SU6656 (as well as a MEK/ERK inhibitor U0126) block the enhanced migration of SSc and AA monocytes. Not surprisingly, CSD (which blocks multiple signaling pathways) was slightly more effective than these inhibitors that block only one pathway. Src-family kinases have been implicated in a variety of activities relevant to monocyte biology including innate immune signaling, responses to cytokines and growth factors, apoptosis, and $G$ protein-coupled signaling [36]. To the best of our knowledge, the current study is the first to link caveolin-1, Src-family signaling, and monocyte migration.

Caveolin-1 and Src have been studied more extensively in other cell types in the context of SSc and fibrosis. Most of these studies involve signaling initiated by TGF $\beta$. In one study focusing on the role of urokinase-type plasminogen activator (uPA) and plasminogen activator inhibitor (PAI) in regulating the epithelial-mesenchymal transformation (EMT) of alveolar type II epithelial cells into myofibroblasts, it was proposed that CSD blocked EMT by inhibiting Src leading to the enhanced expression of uPA and the inhibition of PAI expression [37]. These effects were observed whether EMT was induced by 
bleomycin, TGF $\beta$, or cigarette smoke. Other studies focus on fibroblasts. TGF $\beta$ receptor internalized through caveolin-1 lipid rafts undergoes rapid degradation, thereby decreasing TGF $\beta$ signaling [38]. This mechanism links low caveolin-1 to enhanced TGF $\beta$ signaling. It is noteworthy that TGF $\beta$ is present at high levels in the circulation of healthy AA [9] and SSc patients [39], and TGF $\beta$ treatment decreases caveolin-1 levels in a variety of cell types [12, 38]. Thus, the combination of low caveolin-1 and high TGF $\beta$ may be particularly likely to cause fibrosis because their effects appear to be mutually reinforcing. Src has also been directly linked to TGF $\beta$ signaling. Stimulation of human dermal fibroblasts with TGF $\beta$ activated Src signaling [40]. Treatment of these cells with SU6656 inhibited collagen expression both at the mRNA and protein levels. Similarly, dermal fibrosis induced in mice by bleomycin injection was inhibited by SU6656. Finally, it was observed that TGF $\beta$ can signal through the Src family member c-Abl and that this signaling is independent of canonical TGF $\beta$ signaling through Smad2/3 [41].

\section{Conclusions}

In summary, the current study strongly supports and extends our observations on the role of monocytes and cells derived from monocytes (e.g., fibrocytes) in lung and skin fibrosis and on the predisposition of AA to fibrotic diseases. Our findings highlight the idea that chemokine receptors (e.g., CCR1, CCR2, CCR3) and signaling molecules that control their expression/function (e.g., caveolin1, MEK/ERK, Src/Lyn) are promising targets for novel treatments for fibrotic diseases such as SSc.

\section{Methods}

\section{Blood donors}

Under a protocol approved by the Medical University of South Carolina (MUSC) Institutional Review Board for Human Research, SSc-ILD patients were recruited from the MUSC Scleroderma Clinic. All patients provided written informed consent before enrollment in the study, fulfilled the American College of Rheumatology criteria for SSc [42], and had evidence of ILD [12]. Demographic data for SSc patients and healthy control donors are summarized in Additional file 1: Tables S1 and S2. Note that Additional file 1: Table S1 describes the combined data for all the patients that participated in the entire study, not the patients that participated in a particular experiment.

\section{PBMC and monocyte isolation}

Peripheral blood mononuclear cells (PBMC) were isolated by standard methods [12] by centrifugation on density 1.083 Histopaque cushions. Monocytes were isolated from the PBMC by immunodepletion using a Dynal Monocyte
Negative Isolation Kit (Invitrogen, Carlsbad, CA) resulting in a cell population about $95 \%$ Mac-1+ monocytes [12].

\section{Peptide treatments}

The CSD peptide (amino acids 82-101 of caveolin-1; DGIWKASFTTFTVTKYWFYR) was synthesized as a fusion peptide to the $C$ terminus of the Antennapedia Internalization Sequence (RQIKIWFQNRRMKWKK). The Antennapedia Internalization Sequence (AP) alone was used as control peptide and showed no effect on cell behavior when compared to no added peptide. When treating cells with peptides, stock solutions of peptides (10 $\mathrm{mM}$ in $100 \% \mathrm{DMSO}$ ) were diluted to the indicated final concentrations.

\section{Monocyte migration assays}

Were performed as described [11]. Briefly, SDF-1 (100 $\mathrm{ng} / \mathrm{ml}$ in RPMI $1640 / 1 \%$ BSA), MCP-1 or MCP-3 (50 $\mathrm{ng} / \mathrm{ml}$ in RPMI 1640/1 \% BSA), or unsupplemented RPMI 1640/1 \% BSA were placed into the lower wells of Neuro Probe Multiwell Chemotaxis Chambers (Neuro Probe, Gaithersburg, MD) fitted with $5-\mu \mathrm{m}$ pore size polycarbonate filters. With or without TGF $\beta$ pretreatment (45 min, $10 \mathrm{ng} / \mathrm{ml}$ in RPMI 1640/1 \% BSA), $25 \mu \mathrm{l}$ of cell suspension $\left(5 \times 10^{5}\right.$ cells $\left./ \mathrm{ml}\right)$ was placed in the upper wells. Peptides $(0.1 \mu \mathrm{M})$ or inhibitors (U0126, $0.1 \mu \mathrm{M}$; PP2, $10 \mu \mathrm{M}$; SU6656, $10 \mu \mathrm{M}$ ) were added to the cell suspension prior to placement in the upper chamber. After incubation $\left(2.5 \mathrm{~h}, 37^{\circ} \mathrm{C}, 5 \% \mathrm{CO}_{2}\right)$, filters were removed, fixed, and stained with 4',6-diamidino-2-phenylindole (DAPI) (Invitrogen, Carlsbad, CA). Cells on the underside of the membrane were photographed and counted in six high power fields per condition.

\section{Monocyte signaling/Western blots}

Chemokine-receptor levels and levels of total and activated Src and Lyn were determined by Western blot of sodium dodecyl sulfate-polyacrylamide gel electrophoresis (SDS-PAGE) sample buffer extracts of freshly isolated monocytes. For CSD treatment, monocytes were cultured overnight in 6-well tissue culture plates $\left(2 \times 10^{6}\right.$ cells per well) in RPMI 1640/20 \% fetal calf serum (FCS). Attached cells were then treated for $3 \mathrm{~h}$ with fresh medium (RPMI/ $1 \% \mathrm{BSA}$ ) supplemented with $0.1 \mu \mathrm{M}$ CSD or control peptide. Cells were next washed twice with PBS then extracted with SDS-PAGE sample buffer. Western blots were performed using the indicated antibodies.

\section{Immunocytochemistry}

Images were collected using a Leica DMI 4000B fluorescence microscope. To detect caveolin-1, CCR1, CCR2, and CCR3, cells isolated as described above were cultured overnight in 6-well tissue culture plates $\left(1 \times 10^{6}\right.$ cells per well) on coverslips in RPMI 1640/20 \% FCS. 
Cells were then fixed and permeabilized, labeled with appropriate primary and secondary antibodies, and counterstained with the nuclear stain DAPI.

Immunohistochemistry of human lung tissue sections was performed as described [11]. Briefly, paraffin sections were stained with primary antibodies, appropriate AlexaFluor647- or AlexaFluor555-conjugated secondary antibodies and the nuclear stain DAPI (Invitrogen, Carlsbad, CA). Images were collected using a Leica DMI 4000B fluorescence microscope. Primary antibodies were: rabbit anti-CCR1 (Thermo Fisher Scientific, Rockford, IL, USA; PA1-21629), rabbit anti-CCR2 (Abcam, Cambridge, MA, USA; ab32144), rabbit anti-CCR3 (Abcam, Cambridge, MA, USA; ab36827), rabbit anti-MCP-1 (Abcam, Cambridge, MA, USA; ab 9669), rabbit anti-MCP-3 (Santa Cruz Biotechnology, Santa Cruz, CA, USA; SC-374002), rabbit anti-pSrc-Tyr416 (Cell Signaling Technology, Inc., Danvers, MA, USA; \#2101S), and rabbit anti-pLyn-Tyr507 (Cell Signaling Technology, Inc., Danvers, MA, USA; 04-375).

\section{Mouse experiments}

Mice were treated systemically with bleomycin or vehicle and received CSD or vehicle as recently described $[15,19]$. These studies were performed under protocols approved by the MUSC Institutional Animal Care and Use Committee (AR\#3134, AR\#3029, AR\#3323).

\section{Statistical analyses}

Immunoreactive bands were quantified by densitometry using Image J 1.32 NIH software. Raw densitometric data were processed and analyzed using Prism 3.0 (GraphPad Software Inc.). ANOVA with post hoc Tukey's test was used to evaluate Western blots and monocyte migration. In all figures, ${ }^{* * * *}$ indicates $p<0.002$, **indicates $p<0.01$, and *indicates $p<0.05$.

\section{Additional file}

Additional file 1: Summary of human subject demographics and Table S1 legend. Table S1. Clinical features of SSc patients. Table S2. $\mathrm{AA}$ and Caucasian controls.

\section{Abbreviations}

AA: African American; ANA: antinuclear antibodies; ANOVA: analysis of variance; AP: Antennapedia internalization sequence; ASMA: a-smooth muscle actin; BSA: bovine serum albumin; C: Caucasian; CCL2: 7, Chemokine (C-C motif) ligand 2, 7; CCR1: 2, 3, 5, C-C chemokine receptor types 1, 2, 3, 5 CSD: caveolin-1 scaffolding domain peptide; CXCR4: C-X-C receptor type 4; DAPI: 4',6-diamidino-2-phenylindole; DMSO: dimethylsulfoxide; ECM: extracellular matrix; EMT: epithelial-mesenchymal transformation; ERK: extracellular signal-regulated kinase; FCS: fetal calf serum; FITC: fluorescein isothiocyanate; FVC: forced vital capacity; IL-4: interleukin-4; ILD: interstitial lung disease; IPF: idiopathic pulmonary fibrosis; MAPK: mitogen-activated protein kinase; MCP-1: MCP-3, monocyte chemotactic protein-1, monocyte chemotactic protein-3; MEK: MAPK/ERK kinase; MIP-1a: $\beta$, macrophage inflammatory protein-1a, $\beta$; MUSC: Medical University of South Carolina; PAH: pulmonary arterial hypertension; PAl: plasminogen activator inhibitor; PBMC: peripheral blood mononuclear cells; PBS: phosphate buffered saline; SDF-1: stromal derived factor-1, also known as CXCL12; SDS-PAGE: sodium dodecyl sulfate-polyacrylamide gel electrophoresis; SEM: standard error of the mean; SSc: scleroderma (systemic sclerosis); TGF $\beta$ : transforming growth factor $\beta$; uPA: urokinase-type plasminogen activator.

\section{Competing interests}

While none of the authors have received any financial or non-financial benefit from this work, Drs. Hoffman and Tourkina are the inventors on a use patent $(\# 8,058,227)$ issued to the Medical University of South Carolina on the caveolin-1 scaffolding domain peptide as a treatment for fibrotic diseases.

\section{Authors' contributions}

$\mathrm{RL}$ participated in the study design, experiments, data interpretation, and manuscript preparation. $\mathrm{CR}, \mathrm{BP}, \mathrm{JH}$, and $\mathrm{MZ}$ participated in the experiments. $M B$ participated in the experiments and in editing the manuscript. RMS participated in editing the manuscript. SH and ET participated in the study design, data interpretation, and editing the manuscript. All authors read and approved the final manuscript.

\section{Acknowledgements}

The authors thank coordinators Dana Rosson and Kelley Gibson for recruiting donors and collecting blood samples. This work was supported by grants: NIH NIAMS R01 AR062078, R03 AR056767, and K01 AR054143 (to ET); USARMY/USAMRAA W81XWH-11-1-0508 (to SH), NIH NIAMS P60 AR049459 (Multidisciplinary Clinical Research Center, to RMS), and an NIH NCRR Construction Grant C06 RR015455. ET also received a grant and the Marta Marx Award from the Scleroderma Foundation.

Received: 19 March 2015 Accepted: 8 June 2015

Published online: 20 June 2015

\section{References}

1. Silver RM. Interstitial lung disease of systemic sclerosis. Int Rev Immunol. 1995;12(2-4):281-91.

2. Beall AD, Nietert PJ, Taylor MH, Mitchell HC, Shaftman SR, Silver RM, et al. Ethnic disparities among patients with pulmonary hypertension associated with systemic sclerosis. J Rheumatol. 2007;34(6):1277-82.

3. Nietert PJ, Mitchell HC, Bolster MB, Shaftman SR, Tilley BC, Silver RM. Racial variation in clinical and immunological manifestations of systemic sclerosis. J Rheumatol. 2006;33(2):263-8.

4. Krishnan E, Furst DE. Systemic sclerosis mortality in the United States: 1979-1998. Eur J Epidemiol. 2005;20(10):855-61. doi:10.1007/s10654-005-2210-5.

5. Laing TJ, Gillespie BW, Toth MB, Mayes MD, Gallavan Jr RH, Burns CJ, et al. Racial differences in scleroderma among women in Michigan. Arthritis Rheum. 1997:40(4):734-42. doi:10.1002/1529-0131(199704)40:4<734:.:AIDART20>3.0.CO;2[--]3.

6. Mayes MD, Lacey Jr JV, Beebe-Dimmer J, Gillespie BW, Cooper B, Laing TJ, et al. Prevalence, incidence, survival, and disease characteristics of systemic sclerosis in a large US population. Arthritis Rheum. 2003;48(8):2246-55. doi:10.1002/art.11073.

7. Mayes MD. Scleroderma epidemiology. Rheum Dis Clin North Am. 2003;29(2):239-54

8. Steen V, Domsic RT, Lucas M, Fertig N, Medsger TA, Jr. A clinical and serologic comparison of African American and Caucasian patients with systemic sclerosis. Arthritis Rheum.64(9):2986-94. doi:10.1002/art.34482

9. August $P$, Suthanthiran M. Transforming growth factor beta and progression of renal disease. Kidney Int Suppl. 2003;87:S99-104.

10. Reese C, Perry B, Heywood J, Bonner M, Visconti RP, Lee R, et al. Caveolin-1 deficiency may predispose African Americans to systemic sclerosis-related interstitial lung disease. Arthritis Rheumatol. 2014;66(7):1909-19. doi:10.1002/art.38572.

11. Tourkina E, Bonner M, Oates J, Hofbauer A, Richard M, Znoyko S, et al. Altered monocyte and fibrocyte phenotype and function in scleroderma interstitial lung disease: reversal by caveolin-1 scaffolding domain peptide. Fibrogenesis \& Tissue Repair. 2011;4(1):15. doi:10.1186/1755-1536-4-15.

12. Tourkina E, Richard M, Oates J, Hofbauer A, Bonner M, Gooz P, et al. Caveolin-1 regulates leucocyte behaviour in fibrotic lung disease. Ann Rheum Dis. 2010;69(6):1220-6. doi:10.1136/ard.2009.117580. 
13. Tourkina E, Richard M, Gooz P, Bonner M, Pannu J, Harley R, et al. Antifibrotic properties of caveolin-1 scaffolding domain in vitro and in vivo. Am J Physiol Lung Cell Mol Physiol. 2008;294(5):L843-61. doi:10.1152/ ajplung.00295.2007.

14. Wang XM, Zhang Y, Kim HP, Zhou Z, Feghali-Bostwick CA, Liu F, et al. Caveolin-1: a critical regulator of lung fibrosis in idiopathic pulmonary fibrosis. J Exp Med. 2006;203(13):2895-906. doi:10.1084/jem.20061536.

15. Lee R, Perry B, Heywood J, Reese C, Bonner M, Hatfield CM, et al. Caveolin-1 regulates chemokine receptor 5 -mediated contribution of bone marrowderived cells to dermal fibrosis. Frontiers in Pharmacol. 2014:5:140. doi:10.3389/fphar.2014.00140

16. Olson TS, Ley K. Chemokines and chemokine receptors in leukocyte trafficking. Am J Physiol Regul Integr Comp Physiol. 2002;283(1):R7-28. doi:10.1152/ajpregu.00738.2001.

17. Kumar P, Hosaka S, Koch AE. Soluble E-selectin induces monocyte chemotaxis through Src family tyrosine kinases. J Biol Chem. 2001;276(24):21039-45. doi:10.1074/jbc.M009099200.

18. Distler JH, Akhmetshina A, Schett G, Distler O. Monocyte chemoattractant proteins in the pathogenesis of systemic sclerosis. Rheumatology. 2009;48(2):98-103. doi:10.1093/rheumatology/ken401.

19. Lee R, Reese C, Bonner M, Tourkina E, Hajdu Z, Riemer EC, et al. Bleomycin delivery by osmotic mini-pump: similarity to human scleroderma interstitial lung disease. Am J Physiol Lung Cell Mol Physiol. 2014;306(8):L736-48. doi:10.1152/ajplung.00210.2013.

20. Reese C, Lee R, Bonner M, Perry B, Heywood J, Silver RM, et al. Fibrocytes in the fibrotic lung: altered phenotype detected by flow cytometry. Frontiers in Pharmacol. 2014;5:141. doi:10.3389/fphar.2014.00141.

21. Christmann RB, Hayes E, Pendergrass S, Padilla C, Farina G, Affandi AJ, et al. Interferon and alternative activation of monocyte/macrophages in systemic sclerosis-associated pulmonary arterial hypertension. Arthritis Rheum. 2011;63(6):1718-28. doi:10.1002/art.30318.

22. Pendergrass $S A$, Hayes $E$, Farina $G$, Lemaire $R$, Farber HW, Whitfield ML, et al. Limited systemic sclerosis patients with pulmonary arterial hypertension show biomarkers of inflammation and vascular injury. PLoS One. 2010;5(8), e12106. doi:10.1371/journal.pone.0012106.

23. Carulli MT, Ong VH, Ponticos M, Shiwen X, Abraham DJ, Black CM, et al. Chemokine receptor CCR2 expression by systemic sclerosis fibroblasts: evidence for autocrine regulation of myofibroblast differentiation. Arthritis Rheum. 2005;52(12):3772-82. doi:10.1002/art.21396.

24. Ingersoll MA, Spanbroek R, Lottaz C, Gautier EL, Frankenberger M, Hoffmann $\mathrm{R}$, et al. Comparison of gene expression profiles between human and mouse monocyte subsets. Blood. 2010;115(3):e10-9. doi:10.1182/blood2009-07-235028.

25. Shi C, Pamer EG. Monocyte recruitment during infection and inflammation. Nat Rev Immunol. 2011;11(11):762-74. doi:10.1038/nri3070.

26. Tokuda A, Itakura M, Onai N, Kimura H, Kuriyama T, Matsushima K. Pivotal role of CCR1-positive leukocytes in bleomycin-induced lung fibrosis in mice. J Immunol. 2000;164(5):2745-51.

27. Moore BB, Kolodsick JE, Thannickal VJ, Cooke K, Moore TA, Hogaboam C, et al. CCR2-mediated recruitment of fibrocytes to the alveolar space after fibrotic injury. Am J Pathol. 2005;166(3):675-84

28. Arai M, Ikawa Y, Chujo S, Hamaguchi Y, Ishida W, Shirasaki F, et al. Chemokine receptors CCR2 and CX3CR1 regulate skin fibrosis in the mouse model of cytokine-induced systemic sclerosis. J Dermatol Sci. 2013;69(3):250-8. doi:10.1016/j.jdermsci.2012.10.010.

29. Yanaba K, Komura K, Kodera M, Matsushita T, Hasegawa M, Takehara K, et al. Serum levels of monocyte chemotactic protein-3/CCL7 are raised in patients with systemic sclerosis: association with extent of skin sclerosis and severity of pulmonary fibrosis. Ann Rheum Dis. 2006;65(1):124-6. doi:10.1136/ ard.2005.040782

30. Ong VH, Evans LA, Shiwen X, Fisher IB, Rajkumar V, Abraham DJ, et al. Monocyte chemoattractant protein 3 as a mediator of fibrosis: overexpression in systemic sclerosis and the type 1 tight-skin mouse. Arthritis Rheum. 2003;48(7):1979-91. doi:10.1002/art.11164.

31. Ong VH, Carulli MT, Xu S, Khan K, Lindahl G, Abraham DJ, et al. Cross-talk between MCP-3 and TGFbeta promotes fibroblast collagen biosynthesis. Exp Cell Res. 2009;315(2):151-61. doi:10.1016/j.yexcr.2008.11.001.

32. Denton CP, Shi-Wen X, Sutton A, Abraham DJ, Black CM, Pearson JD. Scleroderma fibroblasts promote migration of mononuclear leucocytes across endothelial cell monolayers. Clin Exp Immunol. 1998;114(2):293-300.
33. Distler JH, Jungel A, Caretto D, Schulze-Horsel U, Kowal-Bielecka O, Gay RE, et al. Monocyte chemoattractant protein 1 released from glycosaminoglycans mediates its profibrotic effects in systemic sclerosis via the release of interleukin-4 from T cells. Arthritis Rheum. 2006;54(1):214-25. doi:10.1002/art.21497.

34. Yamamoto T, Nishioka K. Role of monocyte chemoattractant protein-1 and its receptor, CCR-2, in the pathogenesis of bleomycin-induced scleroderma J Invest Dermatol. 2003;121(3):510-6. doi:10.1046/j.1523-1747.2003.12408.x.

35. Todd NW, Luzina IG, Atamas SP. Molecular and cellular mechanisms of pulmonary fibrosis. Fibrogenesis Tissue Repair. 2012;5(1):11. doi:10.1186/ 1755-1536-5-11.

36. Parsons SJ, Parsons JT. Src family kinases, key regulators of signal transduction. Oncogene. 2004;23(48):7906-9. doi:10.1038/sj.onc.1208160.

37. Marudamuthu AS, Shetty SK, Bhandary YP, Karandashova S, Thompson M, Sathish $V$, et al. Plasminogen activator inhibitor-1 suppresses pro-fibrotic responses in fibroblasts from fibrotic lungs. J Biol Chem. 2015. doi:10.1074/ jbc.M114.601815.

38. Del Galdo F, Lisanti MP, Jimenez SA. Caveolin-1, transforming growth factor-beta receptor internalization, and the pathogenesis of systemic sclerosis. Curr Opin Rheumatol. 2008;20(6):713-9.

39. Vettori S, Cuomo G, ludici M, D'Abrosca V, Giacco V, Barra G, et al. Early systemic sclerosis: serum profiling of factors involved in endothelial, T-cell, and fibroblast interplay is marked by elevated interleukin-33 levels. J Clin Immunol. 2014;34(6):663-8. doi:10.1007/s10875-014-0037-0.

40. Skhirtladze C, Distler O, Dees C, Akhmetshina A, Busch N, Venalis P, et al. Src kinases in systemic sclerosis: central roles in fibroblast activation and in skin fibrosis. Arthritis Rheum. 2008;58(5):1475-84. doi:10.1002/art.23436.

41. Daniels CE, Wilkes MC, Edens M, Kottom TJ, Murphy SJ, Limper AH, et al. Imatinib mesylate inhibits the profibrogenic activity of TGF-beta and prevents bleomycin-mediated lung fibrosis. J Clin Invest. 2004;114(9):1308-16. doi:10.1172/JCl19603.

42. Subcommittee. Preliminary criteria for the classification of systemic sclerosis (scleroderma). Subcommittee for scleroderma criteria of the American Rheumatism Association Diagnostic and Therapeutic Criteria Committee. Arthritis Rheum. 1980;23(5):581-90.

\section{Submit your next manuscript to BioMed Central and take full advantage of:}

- Convenient online submission

- Thorough peer review

- No space constraints or color figure charges

- Immediate publication on acceptance

- Inclusion in PubMed, CAS, Scopus and Google Scholar

- Research which is freely available for redistribution 